УДК 378

\title{
В ПОИСКАХ ОТВЕТОВ НА ДИСКУССИОННЫЕ ПРОБЛЕМЫ ЭКОНОМИЧЕСКОЙ НАУКИ
}

\section{Рыбина Марина Николаевна Быковская Екатерина Николаевна}

к.э.н., доценты, доценты ФГБОУ ВО «Государственный университет управления»

Аннотация: В данной статье презентуется учебное пособие по экономической истории для подготовки бакалавров по направлению 38.03 .01 Экономика / Государственный университет управления, Институт экономики и финансов, в котором представлен широкий круг актуальных проблем экономической истории, имеющий дискуссионный характер. Цель данного учебного пособия - в условиях конструктивного диалога сформировать у студентов умения и навыки аналитического мышления на основе знаний современных проблем экономической науки дискуссионного характера, с привлечением разнообразных информационных источников.

Ключевые слова: предпринимательство, криптовалюта, интернационализация хозяйственных связей, общество знаний и цифровая экономика; процесс индивидуализации в производстве и потреблении, индекс счастья.

\section{IN SEARCH OF ANSWERS TO THE DEBATABLE PROBLEMS OF ECONOMIC SCIENCE}

\begin{abstract}
This article presents a textbook on economic history: for the preparation of bachelors in the direction of 38.03.01 Economics / State University of Management, Institute of Economics and Finance, which presents a wide range of topical problems of economic history, which has a debatable nature. The purpose of this textbook in the conditions of constructive dialogue is to form students' skills and analytical thinking skills based on knowledge of modern problems of economic science of a debatable nature, with the involvement of a variety of information sources.
\end{abstract}


Key words: entrepreneurship, cryptocurrency, internationalization of economic relations, knowledge society and digital economy; the process of individualization in production and consumption, the happiness index.

Учебное пособие «В поисках ответов на дискуссионные проблемы экономической истории» [1] разработано для студентов, изучающих дисциплины «Экономическая история», а также может быть использовано при изучении таких дисциплин как «Экономическая теория», «История экономических учений», «Институциональная экономика».

Можно со всей определенностью сказать, что данное пособие вписывается в современный тренд междисциплинарного (трансдисциплинарного) подхода к высшему образованию. Вместе с этим учебное пособие может эффективно использоваться при дистанционном формате обучения студентов.

Н. Грэгори Мэнкью в своём учебнике «Принципы ЭКОНОМИКС» («Principles of ECONOMICS») пишет: «Даже если экономистам поручат довести до конца хотя бы одно дело, они никогда не придут к согласию» (Д.Б. Шоу). Попробуйте-ка сформулировать более разоблачительное высказывание! Экономистов, как профессиональное сообщество, постоянно критикуют за их взаимоисключающие советы политикам. Президент США Рональд Рейган однажды пошутил, что если бы в игру «Счастливый случай» сыграли экономист, ее ведущий получил бы на 100 вопросов 3000 ответов.

Почему экономисты так часто дают политикам противоречивые ответы?

- Экономисты могут расходиться во мнениях об обоснованности альтернативных позитивных теорий устройства мира.

- Экономисты могут ориентироваться на различные мировоззренческие ценности, что ведет к формированию противоречивых нормативных концепций.

- Возможно, экономисты давно пришли к единому мнению, но их голос заглушают вопли шарлатанов или чудаков от экономики» [2, с 34-35].

Пол Э. Самуэльсон считал, что развитие науки вообще «непрямолинейно». По его мнению, наука должна продвигаться вперед через отрицание, сбросить балласт, когда заходит в тупик, сделав крюк. Дискуссии как раз тот действенны инструмент, который позволяет идти науке вперед, сбрасывая балласт. 
Цель данного учебного пособия заключается в том, чтобы у студентов сформировались умения и навыки аналитического мышления на основе знаний основных проблем экономической теории дискуссионного характера.

Для достижения поставленной цели учебное пособие составлено таким образом, чтобы решались следующие задачи:

в режиме семинарских занятий в проблемной постановке вопроса у студентов вырабатывался навык участия в публичной дискуссии по спорным вопросам экономической истории, а также в условиях конструктивного диалога формировались умения по обсуждению экономических проблем в целом;

в режиме самостоятельной работы студентов вырабатывался навык и формировались умения поиска современной информации по дискуссионным вопросам экономической истории, а также ретроспективного взгляда на выработку ее основного вектора;

в условиях аналитической работы по предмету у студентов выработалось понимание вызовов времени, на которые отвечали те или иные социально-экономические концепции, а также направления и тренды экономической политики тех или иных стран мирового экономического сообщества.

в режиме постижения дисциплины формировались такие навыки, которые позволили бы дискуссионные вопросы экономической истории рассматривать с последующим выходом на публичное обсуждение в рамках семинарских занятий, через призму таких мегатрендов современности как: общество знания и цифровая экономика; глобализация и урбанизация; процесс индивидуализации в производстве и потреблении; влияние руководителей будущего на экономическую и экологическую деятельность хозяйствующих субъектов, на роль и место государства в экосистеме, а также на трудовые обязанности и социальную ответственность коллектива.

Содержание учебного пособия состоит из определенного ряда эссе на заданную тему, снабжено массивом вопросов по каждой теме для проведения дискуссий, а также списком информационных источников для подготовки к ним. Так, в эссе о трансформации предмета и методов исследования экономической науки констатируется, что в научных кругах не утихает полемика о соотношение политической экономии и еconomics (экономической теории в русском переводе этого термина). Поэтому есть все основания 
остановиться, прежде всего, на трансформации названия экономической науки и определении места в ней каждого раздела.

В эссе об этической составляющей рыночных отношений предлагается дискуссия следующего содержания - «Рыночной экономике - ДА, рыночному обществу - НЕТ». Ставится на обсуждение вопрос о том, можно ли принять такой вектор развития человечества? Ответы на эти вопросы, связанные с этическими нормами жизнедеятельности, искали ученые задолго до обустройства рыночного хозяйствования во многих странах. Ответы на этот вопрос ищут многие современные ученые и в современную эпоху формирования новой экономики. Есть мнение, что глобализация сегодня это отношения по поводу РЕНТЫ. Такая постановка вопроса усугубляет проблему этической составляющей рыночных отношений. Однако очень важной чертой либерализма является то, что его представители пытаются решить проблемы нравственных основ капитализма, связать этику и экономическую теорию. По мнению видного американского экономиста Дж. К. Гэлбрэйта, на протяжении столетий ничто так не привлекало экономическое внимание, как необходимость убедить людей, что цена, определяемая рынком, отвечает самым высоким моральным критериям, которые только могут быть предъявлены. Так ли это? Как обстоит дело в российской практике хозяйствования и в процессе использования рыночных механизмов регулирования экономики.

В эссе об обществе потребления и его трансформации в сторону творческого потребления предлагается дискуссия на тему о том, что существует соображение, что общество потребления - это некая метафора, применяемая для обозначения, сложившихся в $\mathrm{XX}$ веке социальноэкономических отношений в большинстве развитых стран, базирующихся на принципах индивидуального потребления. Это явление привлекало и привлекает разных специалистов, которые не могли обойти стороной особенности, противоречия, присущие обществу потребления. Так, во-первых, несмотря на всю метафоричность этого понятия для определения социально-экономического состояния общества развитых стран необходимо зафиксировать основные его характеристики, с вычленением экономической составляющей. Во-первых, привести доводы, которые определяют общество потребления как общество «частного великолепия и общественной нищеты». Во-вторых, обозначить негативные и позитивные стороны этого явления. В-третьих, определить перспективы развития российской жизнедеятельности 
через призму перспектив существования общества потребления в отечественной повседневности бытия, со всей неотвратимостью последствий, сопутствующих этому явлению. В-четвертых, обосновать гипотезу о том, что каково потребление таков и человек. В форме актуализируется содержание.

В эссе «Предпринимательский тип хозяйствования - важнейшее условие конкурентоспособности современной экономической системы» со студентами предлагается провести дискуссию по определению самой сути предпринимательства. В России это явление связывают с прибылью и только, что в свою очередь уходит своими корнями в непонимания различий между бизнесом и предпринимательством. Распространенное определение предпринимательства, предпринимательской деятельности сводится к тому, то это самостоятельная, осуществляемая на свой риск экономическая деятельность, направленная на систематическое получение прибыли от пользования имуществом и/или нематериальными активами, продажи товаров, выполнения работ или оказания услуг. В русском языке слова предпринимательство и бизнес (англ. business - «дело», «предприятие») синонимичны. Однако в современных условиях ставить целью лишь максимизацию прибыли явно недостаточно. Во-первых, предпринимательство - это - entrepreneurship, а антрепренёры обязательно творцы, выдумщики чего-то нового. Во-вторых, создание потребителя и новых потребностей вот что является главным мотивом и критерием предпринимательства, обеспечивающим конкурентоспособность экономической системы в целом. Следуя выводам А. Маршалла, Й Шумпетора и пр., предприниматель - это, прежде всего, инноватор и необходимо разделять предпринимателей на две категории: тех, кто открывает новые и улучшенные методы хозяйствования, и тех, кто следует проторенным путем. Таким образом, есть - предпринимателиноваторы, а есть - бизнесмены, так сказать, «деловары» - дельцы, которые также объективно необходимы для хозяйственной деятельности по тиражированию сложившейся экономической практики.

В эссе «Общественное благосостояние. «Индекса счастья» как показатель социального прогресса страны» констатируется, что современное состояние социально-экономических и политических процессов характеризуется качественными изменениями и небывало сложным переплетением различных, порой совершенно противоречивых тенденций. Так, уже в 2012 году на Давосском форуме в самых либеральных кругах деловой элиты был сделан вывод о том, что капитализм больше неактуален. 
По меткому замечанию Э.Тоффлера, мир переживает «ЭКОСПАЗМ». Можно добавить, что мир переживает не только экономический спазм, но и социально-политический, экологический, нравственный, демографический. В настоящее время особо остро ведется дискуссия о грядущих переменах социально-экономического и политического свойства. Новая экономика подразумевает и «новую организацию» нашей жизни - идет переоценка ценностей, происходит социализация жизни. В практику оценки жизнедеятельности человека ряда стран вводится показатель «индекса счастья〉 как показатель социального прогресса страны ( Международный индекс счастья - Happy Planet Index). Для расчета HPI используются (по версии британского исследовательского центра New Economics Foundation (NEF) три показателя : субъективная удовлетворенность жизнью; ожидаемая продолжительность жизни; состояние экологии. Традиционный подход для сравнения стран по основным макроэкономическим показателям остается до сих пор востребованным и повсеместно используется. Однако сегодня страны мирового сообщества рейтингуются и по другим показателям. Студентам предлагается провести диалог на поставленные вопросы.

В эссе «Криптовалюта: за и против» предлагается дискуссия в связи с констатацией того, что с развитием компьютерных технологий и сетей связи мир вступил в эпоху «электронных денег». Криптовалюта - абсолютно новое платежное средство двадцать первого века, которое имеет ряд существенных отличий от других видов электронных денег. Криптовалюты меняют привычное представление людей о том, какие бывают деньги. В традиционном представлении валюта всегда эмитируется каким-то конкретным государством в лице национального или государственного банка, но криптовалюта децентрализована, это негосударственная, точнее, надгосударственная структура. Дискуссии вызывают в современных условиях и проблемы, связанные с оборотом криптовалют, который пока не регулируется ни одним центральным банком в мире и не имеет эмиссионного центра. Появление неконтролируемых центральными банками цифровых валют делает невозможным проводить денежно-кредитную политику, контролировать размеры предложения денег. Поэтому центральные банки многих стран мира думают над созданием национальных цифровых валют. Некоторые специалисты полагают, что такие цифровые деньги могли бы положить конец доминированию доллара в мировой экономике. В целом перспективы использования криптовалют остаются весьма неопределенными. 
Можно сказать, что криптовалюта - это компьютерный феномен, существующий в пользовательских сетях. Вопрос влияния криптовалюты на мировую экономику - один из самых актуальных вопросов для современных экономистов. В экспертном сообществе нет однозначного ответа на перспективы использования криптоволюты. Остается дискуссионным вопрос о контроле за денежными потоками, которые в бесконтрольном режиме могут приводить к усилению криминализации экономик различных стран по поводу перевода денег за вооружение, незаконные экономические сделки по продаже наркотиков, человеческих органов, предметов антиквариата.

В эссе «Стимулирование экономического роста - поддержание темпов на высоком и оптимальном уровне» предлагается дискуссия на тему того, что в экономической науке определились различные направления, характеризующие изменения в развитии страны в целом. Постулат постоянного экономического роста - основная концепция целого ряда направлений экономической мысли. В западной экономической мысли получила широкое распространение категория «экономический рост», определяющая развитие производства в основном с количественной стороны. Предметом теоретического анализа является динамика потенциального объема производства. Экономический рост трактуется как движение от одного долгосрочного состояния равновесия к другому. В современных западных экономических теориях можно выделить несколько ведущих направления в изучении категории «экономического роста». Первое направление - это неоклассические теории экономического роста, основывающихся на постулатах рыночной саморегуляции (А. Маршалл, Л. Вальрас, М. Фридман, Р. Солоу). Второе направление представлено неокейнсианскими теориями (Д. Тойнби, О. Симомура, С. Фудзино). Третье направление называется эволюционным, которое представлено (Й. Шумпетер, Р. Нельсон и С. Уинтер).

В эссе «Интернационализация хозяйственной жизни - основная тенденция развития мировой экономики» на дискуссию выносится следующая проблема - основной тенденцией развития мировой экономики в современных условиях является интернационализация хозяйственной жизни. Движение по всему миру гигантских потоков людей капитала, товаров, интенсивный обмен информацией определяют лицо и динамику развития на рубеже XX-XXI веков. Для обозначения всех этих процессов применяется термин “глобализация”. Глобализация - это процесс трансформации мирового 
хозяйства в единый общепланетарный рынок капитала, рабочей силы, товаров и услуг. Глобализация означает усиление взаимозависимости и взаимовлияния практически всех сфер общественной жизни и деятельности в области международных отношений: экономики, политики, идеологии, социальной сферы, культуры, образования и науки, экологии, безопасности, образа жизни, самих условий существования цивилизации. С самого начала появления этого термина и по сей день ведутся дискуссии по поводу самого явления, а также определения и характеристики этого понятия. В новых условиях 2020 года все отчетливее звучит точка зрения, что глобализация исчерпала себя. На смену ей приходит «глоколизация». Противоборство, как в теории, так и на практике продолжается.

Дискуссионные вопросы, такие как: распределение природной ренты; распределение богатства вообще и в России, в частности; роль государства как интегратора хозяйственной деятельности; соотношение субъективного и объективного в трактовке истории остаются актуальными и, даже, злободневными по сей день. Дискуссии продолжаются, а тветы на сложные дискуссионные вопросы позволяют оптимизировать результаты конкретной хозяйственной практики.

\section{Список литературы}

1. Е.Н. Быковская, М.Н. Рыбина, Г.П. Харчилава. Учебное пособие по экономической истории для подготовки бакалавров по направлению 38.03 .01 Экономика / Государственный Университет Управления , Институт Экономики и финансов. - Москва: ГУУ, 2021.- с. 91

2. Мэнкью Н.Г. Принципы экономикс. 2-е изд., сокрщ. - СПб: Питер, $2000-496$ c.

() М.Н. Рыбина, Е.Н. Быковская, 2021 